Rakenteiden Mekaniikka (Journal of Structural Mechanics)

Vol. 50, No 3, 2017, pp. 166 - 170

https://rakenteidenmekaniikka.journal.fi/index

https://doi.org/10.23998/rm.65116

(c) The author(s) 2017.

Open access under CC BY-SA 4.0 license.

\title{
Full scale fatigue testing of crankshaft
}

\author{
Jussi Korhonen ${ }^{1}$, Antti Mäntylä Juho Könnö and Tero Frondelius
}

Summary. This article outlines full-scale fatigue testing of crankshafts, in particular with the resonance fatigue testing method. The focus of the paper is the practical implementation of the method.

Key words: crankshaft, fatigue testing

Received 30 June 2017. Accepted 24 July 2017. Published online 21 August 2017

\section{Introduction}

There are two main approaches on fatigue testing of crankshafts: full-scale testing and testing with smaller specimens that are cut from a crankshaft. The latter approach is straightforward and enables the usage of widely available fatigue testing equipment. However, IACS UR M53 Appendix IV [11] states that full-scale testing is required for crankshafts with surface treatment. When the risk volume of a component is not homogeneous, a single cut specimen only represents a small portion of the volume and not the component as a whole. A wrought crankshaft is neither homogeneous nor isotropic, so the original orientation of the cut specimen also affects the observed fatigue life. Full scale testing is done on the actual component, so the effects of surface treatment and the manufacturing process in general are properly represented.

IACS UR M53 Appendix IV [11] outlines the full-scale fatigue testing procedure for crankshafts, but does not go into detail about the practical implementation. The purpose of this paper is to delve further into the technical details of a possible full-scale testing system. First, we have to clarify what is being tested and how, and then it is possible to focus on what is technically required to perform the experiments.

A single test specimen is defined as a section (crank throw) cut from a crankshaft as specified by IACS UR M53 Appendix IV [11]. The ideal load case to be tested is combined bending and torque, simulating the actual engine operation, see crankshaft fatigue calculations examples in $[2,8,9]$. If a combined load case cannot be produced, the experiment will be conducted primarily with a cyclic bending load. The reason is that the bending stress levels are the more critical ones in the actual engine operation compared to the torque stress levels. A means to apply a cyclic bending stress to a

\footnotetext{
${ }^{1}$ Corresponding author. jussi.korhonen@gbw.fi
} 
crankshaft section with a suitably high amplitude and frequency is thus required. For a functioning test setup, a system to measure stress, log measurement data and control the stress amplitude is also required. The main components of the system must endure multiple fatigue experiments without failure, and the system must be safe to operate.

\section{Resonance fatigue testing}

As stated before, a means to direct cyclic stress into a crankshaft section with a reasonably high frequency is required. In the case of, for example, marine crankshafts, the involved forces are tremendous. The tests could be run with hydraulic equipment, but energy consumption would become a problem. IACS UR M53 Appendix IV [11] describes an interesting method: resonance fatigue testing. Suitable structures are attached to a crankshaft section to attain an appropriate natural frequency and vibration mode. The system is then excited near the natural frequency to reach oscillations of desired amplitude and mode, thus creating a fatigue load. The added structures also act as torque arms and help to reach the sought stress amplitude levels. The maintenance of such oscillations near the resonant frequency only requires the energy loss absorbed by friction and internal damping to be made up. Both factors are suitably low in metals. The low internal damping also means that only a moderately small excitation force is needed to maintain large movements corresponding to significant stresses.

In principle, both cyclic bending and torque loads can be attained with fairly simple setups individually. The described method creates a fully reversed fatigue load $(R=-1)$. During engine operation, the crankpin fillets experience an R-ratio of slightly above -1 and the journal fillets slightly below -1 for the bending component of the cyclic loading. If deemed necessary, this can be achieved by introducing a spring-based mean load to the experiment. [11] A draft of a bending case resonance fatigue testing system for a crankshaft section is presented in Figure 1(a).

An operational crankshaft has failed when it can no longer transmit torque. Generally, this means that the crankshaft is in two pieces [7]. In a fatigue test, a reliable means to detect imminent component failure is needed. A two-piece failure would best match actual engine failures when testing crankshaft fatigue properties. However, when doing full scale testing, the components are heavy and an uncontrolled two-piece failure might damage the testing equipment or personnel. Both Chien et al. [1] and Lee and Morrissey [5] describe the use of oil to detect appearing micro cracks. Oil is applied to the critical surface areas during a resonant bending fatigue test of a crankshaft. The test is stopped when four bubbles the size of a pinhead appear on the surface within a quarter inch. Chien et al. [1] experimented with a rolled ductile cast iron crankshaft and Lee and Morrissey [5] with a forged steel crankshafts.

However, both authors conclude that the four-bubble criterion is severely lacking. Chien et al. [1] write that, according to their results, the four-bubble failure criterion might not be associated with the final failure of a crankshaft under cyclic bending. Lee and Morrissey [5] write that the micro cracks associated with the four-bubble failure criterion do not correlate with the final fracture mechanism in cold-rolled crankshafts subjected to bending. They conclude that this is not a valid failure criterion. The failure detection should also work automatically for the planned experiment. This would be extremely difficult to achieve with such visual failure criterion. Spiteri et al. [7] conducted resonant bending fatigue tests with rolled ductile cast iron crankshaft sections. They come to the conclusion that an accelerating shift of natural frequency is well associated with two-piece 


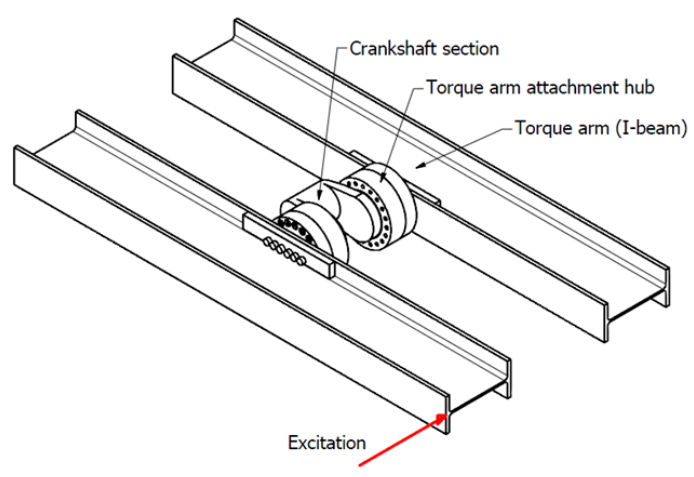

(a) Explanation

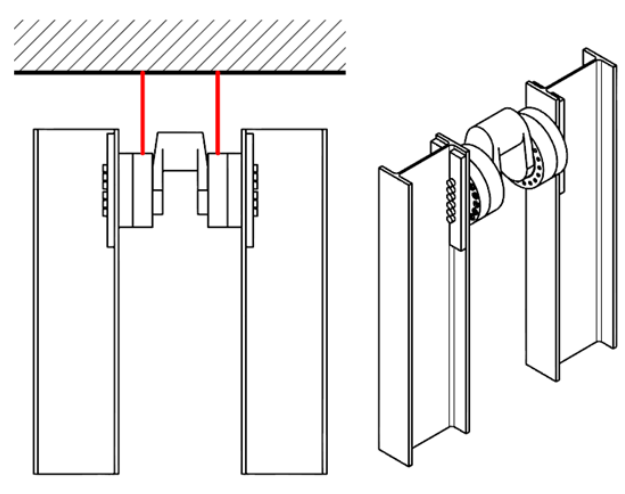

(b) Fixing

Figure 1. Full Scale Crankshaft Test Setup

failure and thus is an effective failure criterion in resonance fatigue testing. This is also a criterion that can be programmed to the control system by using any sensor that is able to track the frequency of the testing vibration, enabling automatic termination of the test on specimen failure. This method is also used in ultrasonic resonance fatigue testing [4].

\section{Mounting of the system}

The beams acting as torque arms of the system will need to be rigidly attached to the journals of the crankshaft segment. The attachment has to transmit the involved forces without failure or sliding of the contact. After exploring different possibilities, it was decided that the optimal method of attachment is a mechanical interference fit. Commercial off-the-shelf options of this type are generally called shrink discs or locking assemblies. In some cases a commercial unit might work, but the dimensions of the journals and the involved forces set certain limits, and an optimal solution is only achieved with a custom locking unit specifically designed for said experiment.

The whole structure must be suspended in the air for it to vibrate freely. This can be done with, for example, web slings. Attachment points must be created near the vibration nodes that have zero displacement. This way the suspension does not damp the desired vibration. There are various possible configurations for the testing system. Figure 1(b) presents a draft of a "suspended tuning fork" configuration. Another possibility is an $\mathrm{H}$-shaped configuration drafted in Figure 1(a). Due to the more balanced shape, it could be suspended in a horizontal position Figure 1(a).

\section{Excitation}

The vibration of the torque arms must be excited by a method that enables accurate control of the resulting amplitude. The factors that contribute to the amplitude of the vibration are both the amplitude and the frequency of the excitation. Either one or both of these will have to be controlled during the experiment.

A simple method of excitation would be an eccentric weight that is rotated by an electric motor. The motor should be isolated from the vibration and installed separately, and the transmission to the eccentric can be done with a flexible shaft. The amplitude of excitation can be modified by changing the radius or mass of the eccentric weight. The frequency can be controlled by altering the rotational speed of the motor. In any 
case, only one of these control options is required for the system to work. For example, Wang and Lv [10] mention the use of a rotating eccentric as an excitation method of a resonant fatigue test. This method would be fairly easy to design and build from scratch if the frequency control is found sufficient. However, if the excitation amplitude is to be controlled during operation, the design will be essentially more complicated.

\section{Measurement and control}

Control is a means to make the outputs of a dynamic system do what is desired of them, even in the presence of unknown disturbances. Control is generally divided into two basic types: open-loop control and closed-loop control. An open-loop control is blind to disturbances, whereas a closed-loop control operates by comparing the actual output to the desired output and adjusting the input accordingly. [3] This means that the actual output must be measured for control purposes. In the case of this experiment, output is the stress amplitude in the crank throw, more precisely in the crank pin fillet. Stress cannot be directly measured in this case, but measuring the strains of the material surface with strain gauges is quite simple and stress can be calculated from the results.

Regarding strain gauge placement, a static stress analysis is needed to determine the critical locations [6]. Strain gauge measurements are needed on both the plain shaft sections and the critical fillet areas to confirm the applied loads [11]. During the actual fatigue test, the strain gauges in the critical fillet area will quickly fail due to fatigue of the strain gauge itself. Because of this, the strain gauges used for controlling the experiment are to be installed on an area where the strain will not exceed their fatigue limit. The outputs of these control strain gauges are compared to the outputs of those on the critical areas during the beginning of an experiment to confirm the desired output used for control. The measured strains should also be logged for further analysis.

As mentioned before, there are three ways to control the stress amplitude. The first one is by controlling the excitation amplitude, the second by controlling the ratio of excitation frequency and natural frequency. The third option is to combine these two. If the control is done by either the first or the second method, it creates a single-input-single-output system. If a combination of the two control methods is used, it will be a multi-inputsingle-output system. The system can also be classified as a time variant. The resulting strain amplitude depends on the excitation force and the amount of amplification. The crucial detail is that the amplification does not depend purely on the excitation frequency but on the ratio of the excitation frequency and natural frequency of the system. During the experiment, the natural frequency of the system may change.

Usually dynamical models of real systems are nonlinear [3]. This also applies to resonance fatigue testing. The response of the excitation amplitude control should be almost linear, but the response of the frequency control is strongly nonlinear. Thus, nonlinear control methods must be employed. A relatively simple and popular approach is gain scheduling. This approach is based on decomposing a nonlinear control task into a number of linear sub-problems. As a result, the well-established and familiar linear design methods can be used to solve nonlinear control problems.

\section{References}

[1] W. Y. Chien, J. Pan, D. Close, and S. Ho. Fatigue analysis of crankshaft sections under bending with consideration of residual stresses. International Journal of Fatigue, 
27(1):1-19, 2005. ISSN 0142-1123. URL https://doi.org/10.1016/j.ijfatigue. 2004.06 .009 .

[2] Tero Frondelius, Pasi Halla-aho, and Antti Mäntylä. Crankshaft development with virtual engine modelling. In CIMAC Congress Helsinki, 2016.

[3] R. F. Gans. Mechanical systems, a unified approach to vibrations and controls. pages 1-437. Springer International Publishing, 2016.

[4] Jussi Korhonen, Juha Kuoppala, Miikka Väntänen, Joona Vaara, Mikko Turunen, Panu Kämäräinen, Jarkko Laine, Aulis Silvonen, and Tero Frondelius. Qt-steel very high cycle fatigue testing with ultrasonic. Rakenteiden Mekaniikka, 50(3):304-308, 2017. URL https://doi.org/10.23998/rm.65059.

[5] Y. Lee and W. Morrissey. Uncertainties of experimental crankshaft fatigue strength assessment. International Journal of Materials and Product Technology, 16(4):379392, 2001. ISSN 1741-5209. URL https://doi.org/10.1504/IJMPT.2001.001266.

[6] S. S. Shinde, C. S. Pathak, and M. Ukhande. Fatigue life assessment of crankshaft under bending and torsional loading. International Journal of Engineering Research \& Technology, 2(11):2197-2201, 2013. ISSN 2278-0181.

[7] P. Spiteri, S. Ho, and Y. Lee. Assessment of bending fatigue limit for crankshaft sections with inclusion of residual stresses. International Journal of Fatigue, 29(2): 318-329, 2001. ISSN 0142-1123. URL https://doi.org/10.1016/j.ijfatigue. 2006.03 .009 .

[8] Ilkka Väisänen, Antti Mäntylä, Antti Korpela, Teemu Kuivaniemi, and Tero Frondelius. Medium speed engine crankshaft analysis. Rakenteiden Mekaniikka, 50(3): 341-344, 2017. URL https://doi.org/10.23998/rm.64916.

[9] Miikka Väntänen, Joona Vaara, Jukka Aho, Jukka Kemppainen, and Tero Frondelius. Bayesian sequential experimental design for fatigue tests. Rakenteiden Mekaniikka, 50(3):201-205, 2017. URL https://doi .org/10.23998/rm. 64924.

[10] Zhi Ming Wang and Peng Min Lv. Crankshaft fatigue test and statistical distribution of fatigue experimental data. In Applied Mechanics and Materials, volume 401, pages 93-96. Trans Tech Publ, 2013.

[11] CIMAC WG4. Guidance for evaluation of fatigue tests. In IACS UR M53, Appendix IV, 2009.

Jussi Korhonen

Global Boiler Works Oy

Lumijoentie 8, 90400 Oulu

jussi.korhonen@gbw.fi

Antti Mäntylä, Juho Könnö, Tero Frondelius

Wärtsilä

Järvikatu 2-4, 65100 Vaasa

antti.mantyla@wartsila.com, juho.konno@wartsila.com tero.frondelius@wartsila.com 